\title{
An Analysis of the Application of the Suggestions of Clinical Practice Guideline for Ostomy Care in China:A Cross-Sectional Investigation
}

\author{
Jing WANG, Shu-Jin YUE*, Dong-Qun XUE, Zi-Pan WANG, Yu LI, Zhi-Qi CHEN, Dong-Qin KANG, Qi LIU \\ School of Nursing, Beijing University of Chinese Medicine, Beijing 104488, China
}

\begin{abstract}
Background: Clinical practice guidelines refer to the guidance provided by the expert system to help medical staff and patients decide on appropriate treatments for a specific clinical situation, mainly including guidelines based on expert consensus and evidence-based guidelines. Since there is no research and clinical application of a specific stoma guidance in China. It is of great significance to understand the application status of the recommended guidelines and the influencing factors in promoting the development of stoma care.

Purpose: To investigate the application status of recommended clinical practice guidelines for stoma nursing in China, and to analyse the reasons for the knowledge and application of recommendations.

Methods: The Questionnaire on the Application of Recommendations in Clinical Practice Guidelines for Ostomy Nursing was adopted.

Results: We collected 195 questionnaires and 183 valid questionnaires were available. (1) The average knowledge rate of a total of 31 recommendations was $73.65 \%$. The main reasons for unknown were insufficient dissemination and lack of training. (2) The average application rate of the 31 recommendations was $58.08 \%$. The overall satisfaction rate of people who used them was high. The main reasons for not applying recommendations were complex.

Conclusions: Different levels of recommendations awareness and application are different. There is a lack of evidence-based guidelines for clinical practice in ostomy nursing in the field of stoma care in China, which limits the scientific development of stoma care to a certain extent. However, this study provides reference for the future construction of a guidebook adapted to our country's localization.
\end{abstract}

Key words: Clinical practice guideline; Recommendations; Application status; Ostomy care

\section{Background}

Clinical practice guidelines refer to the guidance provided by experts to help medical staff and patients carry out

\section{"Corresponding Author:}

Shu-jin YUE, RN, PhD, Professor, School of Nursing, Beijing University of Chinese Medicine, Liang Xiang University Town, Beijing 104488, China E-mail: yueliang874@I26.com

Received: March 31 2019, Revised:April 15 2019,Accepted:April 18 2019, Online: May 152019 appropriate treatment for a specific clinical situation, mainly including guidelines based on expert consensus and evidence-based guidelines. A number of clinical practice guidelines for stoma care have been developed abroad, such as the Registered Nurses' Association of Ontario (RNAO) guidelines for Ostomy Care and 
Management ${ }^{[1]}$, Wound, Ostomy, and Continence Nurses Society (WOCNS) Best Practice Guidelines for Managing Patients with Stoma ostostomy ${ }^{[2]}$, Pediatric Ostomy Care Best practice guidelines ${ }^{[3]}$. At present, with the development of stoma care, the chances for nurses in China to receive training and education have been increased, and the opportunity for access to recommendation of foreign guidelines has increased. Some guidelines have been read by nurses and applied to the clinical practice of stoma.

The application of clinical practice guidelines will be influenced by such factors as the guideline itself, patients, medical staff and the environment ${ }^{[4-7]}$. The purpose of this study is to investigate the application status and analyse the reasons for the promotion of the clinical application of the guidelines, and to explore the application status of guidelines developed in foreign countries. However, there is no research on the quality of the guidelines for stoma care, nor on the current status of the application of the recommendations of high-quality stoma care guidelines in China, nor on the existing problems in the application of the recommendation. To a certain extent, this limits the scientific and sustainable development of stoma care.

The purpose of this study is to investigate the status on ostomy nursing of the application of the recommendations of clinical practice guidelines in China, and to analyse the influencing factors about their application so as to promote the development of evidence-based practice in stoma nursing, improve the quality of stoma nursing in China, and promote nursing science and professional development.

\section{Materials and Methods}

\section{Design}

This study used a cross-sectional survey design.

\section{Ethical considerations}

The study was approved by the Ethics committee of Beijing University of Chinese Traditional Medicine. An approval from the local ethics committees from each hospital was acquired. All nurses participating in this study gave an informed consent.

\section{Participants and data collection}

The study population consisted of nurses working in hospitals engaged in stoma care for 3 years and above, familiar with stoma care knowledge and skills. We sent the informed consent and obtained the consent and participants volunteered to participate in this study. Those who withdrew from the investigation halfway through the survey and those who had mental or psychological problems and were currently taking antipsychotic drugs were excluded. The survey areas include South China, North China, West China and East China, with Beijing and Jiangsu as the main areas. Other regions also participated in some of the surveys. Details are as follows: North China: Beijing, Hebei, Tianjin, Liaoning, Inner Mongolia, East China: Jiangsu, Zhejiang, Anhui, Shandong, Fujian, West China: Sichuan, Chongqing, Yunnan, South China: Guangdong, Hainan, Guizhou. The sample size (n) was 5-10 times the number of items in the research questionnaire except the general data. Considering 20\% of the questionnaires ineffective, the final sample size is $(1+20 \%) * \mathrm{n}$. In this study, the number of recommended entries for the survey was 31 and the minimum sample size was estimated to be $(1+20 \%) * 5 * 31=186$. Given the constraints of time and conditions, it was expected to collect 200 questionnaires.

This study used a convenience sampling method, through field distribution and e-mail. The data collectors who received unified training distributed the field questionnaire for qualified nurses and received them on the spot, in addition, the researcher himself was invited in "We Chat"-the Group of National Stoma incontinence incontinence. Nurses participated in the study on a voluntary basis with, informed consent, received researchers, one-to-one guidance, and the questionnaire was collected promptly. Respondents filled the questionnaire independently without interacting with each other so as not to affect the results. The questionnaires were carefully checked for any omissions, respondents were numbered, rather than identified by none, to protect the privacy of respondents. The incomplete questionnaires were regarded as invalid and excluded. 


\section{Instrument}

This research used a self-compiled questionnaire "Application of clinical practice guidelines" In this study, and "the Planned Behavior Theory" was selected as the theoretical basis for compiling the questionnaire. Fiftyfive recommended A-level guidelines were selected by 2 nursing Master degree candidates who classified and collated the recommendations independently. After experts consultation, the questionnaire was designed as follows: General Information, Cognition of Recommended Opinions, Application of Recommended Opinions, and Clinical Implementation in the Future, with a total of 9 items of general information and 31 items on the questionnaire subjects. The item-level content validity index (I-CVI) of each evaluation item is 1.00 , and the content validity of the total questionnaire is scale-level content validity index (S-CVI) is 1.00 . The validity of the questionnaire is good. Test-retest reliability was good, with very little difference between the two test results.

\section{Statistical analysis}

The SPSS16.0 statistical software package was used to analyze the data obtained. $P<0.05$ was taken as the level of statistical significance. Data were analysis descriptively using frequency and percentage.

\section{Results}

Demographic characteristics of the respondents In this study, a total of 200 questionnaires were distributed and 195 were recovered with a response rate of $97.5 \%$. 183 valid questionnaires were recovered, constructing $93.85 \%$ of the questionnaires. Of the 183 nurses who participated in the survey, $98.36 \%$ were women; the largest age group was mostly $31-40$ years old, and $81.42 \%$ had a bachelor degree or above. $97.81 \%$ of nurses came from 3A General Hospital. (Table 1)

Knowledge of ostomy nursing clinical practice guideline recommendations

In terms of knowledge, the average knowledge rate of the 31 recommendations for ostomy nursing was $73.65 \%$. There were 14 recommendations with a knowledge rate of $\geq 80 \%$, while 10 recommendations with a knowledge rate
Table 1 Demographic data of study subjects $(n=183)$

\begin{tabular}{|c|c|}
\hline General information & Number (\%) \\
\hline \multicolumn{2}{|l|}{ Age (years) } \\
\hline $20-30$ & $55(30.05)$ \\
\hline $31-40$ & $96(52.46)$ \\
\hline $41-50$ & $27(14.75)$ \\
\hline $51-60$ & $5(2.73)$ \\
\hline$>60$ & $0(0.00)$ \\
\hline \multicolumn{2}{|l|}{ Gender } \\
\hline male & $3(1.64)$ \\
\hline female & $180(98.36)$ \\
\hline \multicolumn{2}{|l|}{ Education level } \\
\hline College & $34(18.58)$ \\
\hline Bachelor & $144(78.69)$ \\
\hline Master & $5(2.73)$ \\
\hline Doctor & $0(0.00)$ \\
\hline \multicolumn{2}{|l|}{ Job title } \\
\hline Nurse & $19(10.38)$ \\
\hline Junior nurse & $75(40.98)$ \\
\hline Intermediate nurse & $78(42.62)$ \\
\hline Deputy Chief Nurse & $7(3.83)$ \\
\hline Chief nurse & $4(2.19)$ \\
\hline \multicolumn{2}{|l|}{ Hospital level } \\
\hline Three level A & $179(97.81)$ \\
\hline Three level B & $4(2.19)$ \\
\hline \multicolumn{2}{|c|}{ Specialist nurse/Stoma therapist } \\
\hline yes & $125(68.31)$ \\
\hline no & $58(31.69)$ \\
\hline \multicolumn{2}{|l|}{ Working lifetime (years) } \\
\hline $3-5$ & $31(16.94)$ \\
\hline $6-10$ & $49(26.78)$ \\
\hline$\geq 10$ & $103(56.28)$ \\
\hline \multicolumn{2}{|c|}{ Engaged in stoma care (years) } \\
\hline $3-5$ & $95(51.91)$ \\
\hline $6-10$ & $54(29.51)$ \\
\hline$\geq 10$ & $34(18.58)$ \\
\hline
\end{tabular}


of $60 \%-80 \%$, and 7 recommendations with a knowledge rate of $<60 \%$. Recommendation No.9 "Post-ostomy health education should address key issues related to a particular type of ostomy" had the highest knowledge rate of $88.52 \%$. Recommendation No.8 "Pay attention to the health-related quality of life (HRQOL) after ostomy in different patients" had the lowest knowledge rate of $37.16 \%$, which is concerned progressive muscle relaxation training as part of routine care given to ostomy patients. (Table 2)

Ways of learning about the recommendations mainly included professional learning and training, peer exchanges, reference to periodical literature and reference guides. Among the reasons for lack of knowledge, the main ones were lack of publicity and lack of training and education, while other reasons accounted for a relatively small proportion.

\section{Application of clinical practice guidelines for ostomy nursing}

In terms of application, the overall average utilization rate of the 31 recommendations was $58.08 \%$. The average utilization rate of A-level recommendations was $36.34 \%$, and the average utilization rate of B-level was $62.49 \%$. The reasons for not applying recommendations included: complicated and not easy to implement; the clinic had a fixed treatment and care programme; work overload; lack of attention and support departments, and lack of related equipment resources.

Among the respondents who applied the recommendation, the satisfaction rate with 12 recommendations was $\geq 90 \%$, the satisfaction rate with 16 recommendations was $80 \%$ $90 \%$, and the satisfaction rate with the 3 recommendations was $70 \%-80 \%$. The highest satisfaction rate $(95.18 \%)$ was for recommendation No.16, "Do not insert glycerin into the colostomy for excretion". The lowest satisfaction rate $(71.19 \%)$ was for Recommendation No.4, "Health guidance on intimacy and sexual functions of ostomy/ companion". Three items had a satisfaction rate $<80 \%$. The main reasons for dissatisfaction were poor applicability, content was not easy to implement, and poor patient compliance. (Table 3 and Table 4)

\section{Discussion}

\section{Knowledge and application of recommended opinions in clinical practice guideline of stoma nursing}

The average knowledge rate of the 31 ostomy recommendations was moderate $(75.65 \%)$. In the aspect of the rate of application of recommended opinions, the application rate of 17 recommendations was higher than $60 \%$. Among the groups applying recommendation, the application satisfaction rate was high. The results of this study show that clinical nurses have a variety of ways to understand the recommendations, mainly including professional learning and training, peer exchange, reference to periodical literature and reference guides. Encouraging nurses to participate in on-the-job training and education activities is conducive to the exchange of evidence-based experience among colleagues and the dissemination of knowledge, and enhances nurses' evidence-based knowledge and comprehensive research capabilities.

The 2 A-level recommendations in this study were respectively Opinions 4 "Health care workers are able to provide health guidance to patients / companions for intimate behavior and sexual function and Opinion 17 "Consulting a registered dietitian on how to care for stoma patients at risk or having nutritional complications". These were presented by the RNAO organization in the Guide to Ostomy Care and Management issued in $2009^{[8]}$, and their knowledge rate and application rates were less than $50 \%$, lower than the overall level. On the issue of sexual health education for patients with stoma, several researches ${ }^{[9]}$ in China and abroad have shown that the change of in manner of defecation in patients with ostomy, the gender pressure of spouses, social relations and other factors will lead to a decline of sexual life of patients, thus affecting their overall quality of life. And Reese et al. ${ }^{[10]}$ also point out that sexual problems are one of the major problems that affect the postoperative quality of life of patients. 
Table 2 Knowledge of recommended comments (sorted by descending order of knowledge rate)

\begin{tabular}{|c|c|c|c|c|}
\hline $\begin{array}{l}\text { Recommendation number } \\
\text { (Appendix) }\end{array}$ & Recommendation level & Quality of evidence & Known(\%) & Unknown(\%) \\
\hline 9 & $\mathrm{~B}$ & III & $162(88.52)$ & $21(11.48)$ \\
\hline 5 & $\mathrm{~B}$ & II & $160(87.43)$ & $23(12.57)$ \\
\hline 3 & $\mathrm{~B}$ & II & $158(86.34)$ & $25(13.66)$ \\
\hline 19 & $\mathrm{~B}$ & II-III & $158(86.34)$ & $25(13.66)$ \\
\hline 6 & $\mathrm{D}$ & III & $158(86.34)$ & $25(13.66)$ \\
\hline 1 & $\mathrm{~B}$ & I & $156(85.25)$ & $27(14.75)$ \\
\hline 20 & $\mathrm{C}$ & IV-V & $156(85.25)$ & $27(14.75)$ \\
\hline 11 & $\mathrm{~B}$ & II-III & $154(84.15)$ & $29(15.85)$ \\
\hline 21 & $\mathrm{~B}$ & II & $152(83.06)$ & $31(16.94)$ \\
\hline 18 & $\mathrm{D}$ & III-IV & $152(83.06)$ & $31(16.94)$ \\
\hline 14 & $\mathrm{~B}$ & II-III & $151(82.51)$ & $32(17.49)$ \\
\hline 10 & $\mathrm{C}$ & IV-V & $151(82.51)$ & $32(17.49)$ \\
\hline 23 & $\mathrm{~B}$ & II-III & $150(81.97)$ & $33(18.03)$ \\
\hline 13 & $\mathrm{D}$ & IV & $147(80.33)$ & $36(19.67)$ \\
\hline 12 & $\mathrm{~B}$ & II-III & $142(77.60)$ & $41(22.40)$ \\
\hline 30 & $\mathrm{D}$ & IV & $142(77.60)$ & $41(22.40)$ \\
\hline 25 & $\mathrm{D}$ & III-IV & 141(77.05) & $42(22.95)$ \\
\hline 29 & $\mathrm{D}$ & IV & 141(77.05) & $42(22.95)$ \\
\hline 22 & $\mathrm{D}$ & III & $134(73.22)$ & $49(26.78)$ \\
\hline 2 & None & None & $130(71.04)$ & $53(28.96)$ \\
\hline 7 & $\mathrm{D}$ & III & $129(70.49)$ & $54(29.51)$ \\
\hline 24 & B & II & $128(69.95)$ & $55(30.05)$ \\
\hline 28 & $\mathrm{D}$ & IV & $124(67.76)$ & $59(32.24)$ \\
\hline 26 & $\mathrm{~B}$ & I & $122(66.67)$ & $61(33.33)$ \\
\hline 4 & $\mathrm{~A}$ & I & $109(59.56)$ & $74(40.44)$ \\
\hline 27 & $\mathrm{D}$ & IV & $108(59.02)$ & $75(40.98)$ \\
\hline 17 & A & II & $103(56.28)$ & $80(43.72)$ \\
\hline 31 & $\mathrm{D}$ & IV & $103(56.28)$ & $80(43.72)$ \\
\hline 16 & $\mathrm{~B}$ & I & $96(52.46)$ & $87(47.54)$ \\
\hline 15 & $\mathrm{D}$ & III-IV & $93(50.82)$ & $90(49.18)$ \\
\hline 8 & $\mathrm{~B}$ & I & $68(37.16)$ & $115(62.84)$ \\
\hline Overall average rate & - & - & $73.65 \%$ & $26.35 \%$ \\
\hline
\end{tabular}


Table 3 Recommended applications (Sorted by Application Rate, $n=183$ )

\begin{tabular}{|c|c|c|c|c|}
\hline $\begin{array}{c}\text { Recommendation } \\
\text { number (Appendix) }\end{array}$ & $\begin{array}{c}\text { Recommendation } \\
\text { level }\end{array}$ & Quality of evidence & $\begin{array}{c}\text { The number of } \\
\text { applications (\%) }\end{array}$ & $\begin{array}{c}\text { Satisfaction } \\
\text { number }(\%)\end{array}$ \\
\hline 9 & $\mathrm{~B}$ & III & $153(83.61)$ & $139(90.85)$ \\
\hline 20 & $\mathrm{C}$ & IV-V & $151(82.51)$ & $134(88.74)$ \\
\hline 19 & $\mathrm{~B}$ & II-III & $147(80.33)$ & $139(94.56)$ \\
\hline 6 & $\mathrm{D}$ & III & $146(79.78)$ & $132(90.41)$ \\
\hline 11 & $\mathrm{~B}$ & II-III & $137(74.86)$ & $129(94.16)$ \\
\hline 18 & $\mathrm{D}$ & III-IV & $134(73.22)$ & $126(94.03)$ \\
\hline 13 & $\mathrm{D}$ & IV & $132(72.13)$ & $125(94.70)$ \\
\hline 3 & $\mathrm{~B}$ & II & $131(71.58)$ & $107(81.68)$ \\
\hline 1 & $\mathrm{~B}$ & $\mathrm{I}$ & $130(71.04)$ & $110(84.62)$ \\
\hline 5 & $\mathrm{~B}$ & II & $130(71.04)$ & $115(88.46)$ \\
\hline 21 & $\mathrm{~B}$ & II & $127(69.40)$ & $114(89.76)$ \\
\hline 10 & $\mathrm{C}$ & IV-V & $125(68.31)$ & $105(84.00)$ \\
\hline 30 & $\mathrm{D}$ & IV & $125(68.31)$ & $116(92.80)$ \\
\hline 12 & $\mathrm{~B}$ & II-III & $121(66.12)$ & $112(92.56)$ \\
\hline 14 & $\mathrm{~B}$ & II-III & $121(66.12)$ & $111(91.74)$ \\
\hline 23 & $\mathrm{~B}$ & II-III & $121(66.12)$ & $106(87.60)$ \\
\hline 29 & $\mathrm{D}$ & IV & $119(65.03)$ & $111(93.28)$ \\
\hline 28 & $\mathrm{D}$ & IV & $96(52.46)$ & $85(88.54)$ \\
\hline 2 & None & None & $95(51.91)$ & $73(76.84)$ \\
\hline 24 & $\mathrm{~B}$ & II & $93(50.82)$ & $72(77.42)$ \\
\hline 25 & $\mathrm{D}$ & III-IV & $90(49.18)$ & $81(90.00)$ \\
\hline 22 & $\mathrm{D}$ & III & $84(45.90)$ & $74(88.10)$ \\
\hline 16 & $\mathrm{~B}$ & $\mathrm{I}$ & $83(45.36)$ & $79(95.18)$ \\
\hline 7 & $\mathrm{D}$ & III & $81(44.26)$ & $69(85.19)$ \\
\hline 17 & A & II & $74(40.44)$ & $62(83.78)$ \\
\hline 26 & $\mathrm{~B}$ & I & $69(37.70)$ & $58(84.06)$ \\
\hline 15 & $\mathrm{D}$ & III-IV & $64(34.97)$ & $55(85.94)$ \\
\hline 31 & $\mathrm{D}$ & IV & $61(33.33)$ & $54(88.52)$ \\
\hline 4 & $\mathrm{~A}$ & I & $59(32.24)$ & $42(71.19)$ \\
\hline 27 & $\mathrm{D}$ & IV & $58(31.69)$ & $51(87.93)$ \\
\hline 8 & $\mathrm{~B}$ & I & $38(20.77)$ & $31(81.58)$ \\
\hline Overall average rate & - & - & $58.08 \%$ & - \\
\hline
\end{tabular}

Table 4 Satisfaction rate $<80 \%$ of the recommended reasons (multiple choice)

\begin{tabular}{|c|c|c|c|c|c|c|c|c|c|c|}
\hline $\begin{array}{c}\text { Recommendation } \\
\text { content }\end{array}$ & $\begin{array}{l}\text { Satisfaction } \\
\text { rate }(\%)\end{array}$ & $\begin{array}{l}\text { Number of } \\
\text { unsatisfactory } \\
\text { applications }\end{array}$ & $1(\%)$ & $2(\%)$ & $3(\%)$ & $4(\%)$ & $5(\%)$ & $6(\%)$ & $7(\%)$ & $8(\%)$ \\
\hline $\begin{array}{l}\text { Provide viable rreatment options for } \\
\text { patients who have ulcerative colitis } \\
\text { polyps }\end{array}$ & 76.84 & 22 & 9.09 & 18.18 & 9.09 & 9.09 & 0.00 & 77.27 & 4.55 & 4.55 \\
\hline $\begin{array}{l}\text { the potential impact and guidance } \\
\text { about Intimate behavior and sexual } \\
\text { function }\end{array}$ & 71.19 & 17 & 23.53 & 35.29 & 47.06 & 5.88 & 0.00 & 23.53 & 0.00 & 23.53 \\
\hline Develop an appropriate care plan & 77.42 & 21 & 4.76 & 38.10 & 38.10 & 23.81 & 0.00 & 28.57 & 14.29 & 4.76 \\
\hline
\end{tabular}

Notes: 1 unsafe; 2 poor applicability; 3 complex not easy to implement; 4 restrictions on the autonomy of health care workers; 5 language disorders; 6 poor patient compliance; 7 high cost; 8 other 
The RNAO Guide, 8 states that caregivers should pay attention to listening, supporting and encouraging patients to communicate with their spouses about sex-related issues and include sex education in stoma care. In regard to the prevention and management of nutritional complications in patients with stoma, nutritional status directly affects the postoperative recovery and quality of life in patients with stoma. Physical, psychological or lifestyle changes can easily lead to excessive obesity or weight loss, eating difficulties and other common nutritional complications ${ }^{[8]}$. The results of this study show that Chinese nurses have poor management of nutritional complications, and there is mainly related to the clinical establishment of a fixed treatment and care programme and the lack of emphasis on support by departments.

The results of this study show that the average knowledge rate of B-level recommendations is higher than that of other levels (76.39\%), The B-level recommendations of knowledge and application was good. However, the knowledge and application of different recommendations varied and presented the following features.

is Knowledge and application of ostomy nursing health education and management of complications was better. Ten recommendations with better knowledge and application was included 3 recommendations on "Health Education", and 2 recommendations on "Prevention and Management of Ostomy Complications," showing the health education and prevention and management of disease were major concerns in stoma care.

is Three recommendations in this study mainly introduced the contents and importance of health education before and after ostomy. All of them were recommended by $5 \mathrm{~A}$-level guidelines ${ }^{[2,8,11-13]}$. The rates of knowledge and application are high, especially for the highest scoring recommendation, No.9, indicating that clinical nurses have recognized the importance of health education for patients and their families before and after ostomy.

is There are many studies on the forms of health education in China. However, there are few studies on specific health education content, which is similar to the finding by Phatak et al. ${ }^{[14]}$ in the United States. Therefore, the $3 \mathrm{~B}$-level recommendations that are known and applied well in this study may provide reference for the future research on the content of clinical ostomy nursing education in China. Ostomy nurses know well about community ostomy care, but the application status is poor, which mainly due to busy work and its complexity, and the reasons for the dissatisfaction toward application were difficult to implement and poor patient compliance. On the one hand, the reason for the poor applicability is related to the late initiation of community ostomy care in China, the incomplete exchange mechanism between general hospitals and community hospitals, and the limited quantity and quality of community nursing human resources, and the community nurses' lack of ostomy nursing related education and training. On the other hand, patient compliance may be due to lack of trust in community hospital. In foreign developed countries, where community nurses' functions, management modes, community health education and so on are better developed ${ }^{[15]}$. China can learn from the guidelines recommended, with reference to foreign experience to develop community ostomy care.

is "Progressive Muscle Relaxation Exercise" is known and applied poorly. The recommendations for "progressive muscle relaxation exercises" presented in this study was presented by the RNAO guidelines ${ }^{[8]}$ and the evidence was graded as Level I. The recommendation suggests that progressive muscle exercise may help reduce anxiety and improve quality of life in patients with ostomy. Some countries have applied the therapy to cancer, migraine, fatigue, sleep quality, etc., with good effect ${ }^{[16-20]}$. This study found that the reason for the low knowledge and application rate of recommendations "progressive muscle relaxation exercise" in China may relate to non-universal clinical application of this therapy. We can learn from this opinion, and actively carry out relevant research, and promote application of the recommendation local practice. 
is The results of this study show that some Level $\mathrm{C}$ recommendations, although of lower rank, are better known and applied, for example, the highest application rate was recommendation No.20. However, the quantity and quality of existing research in related fields are limited. Therefore, in the future, we should actively conduct high-quality original research on the above important issues of stoma care, explore high-level evidence and guide based on high-quality evidence, so as to better guide the clinical practice of stoma care.

\section{Analysis of the reasons for low knowledge rate of recommendation of clinical practice guidelines for ostomy nursing}

The results of this study show that professional learning and training are the most important ways of learning. However, ordinary nurses receive less training and education. Therefore, by enriching the forms of training and education, ordinary nurses should be given more opportunities to receive training and education. This will not only facilitate the exchange of evidencebased experience among peers and the dissemination of knowledge, but also enhance the evidence-based knowledge and scientific research on nurses' abilities.

In addition, inadequate promotion of guidelines is also an important factor influencing the knowledge of recommended opinions in this study, which is similar to the findings of Moreno et al. ${ }^{[21]}$ which also pointed out that the poor promotion of Chinese guidelines is not only due to training and education, but also the poor publication mechanism. There are few specialized guide databases or public network platforms, except for the Chinese clinical guideline library set up by the National Health Committee's website and Peking University's EvidenceBased Medicine Center. There are few guidebooks or public network platforms, which makes it difficult for nurses to obtain guides conveniently. Even though these guidelines can be obtained directly from the public network platforms and periodicals that have published the guidelines, the proportion of highly educated nurses in China was relatively low and Chinese Ostomy nursing started late. Most clinical nurses, according to Wang
Dandan $^{[22]}$, lack scientific research knowledge, literature retrieval ability, evidence-based knowledge reserve, and English reading ability.

There is no Chinese research on the clinical practice guidelines for ostomy nursing ${ }^{[23]}$, which limits the clinical nurses' acquisition and understanding of foreign guides. Therefore, China can refer to the existing guideline publishing platforms in foreign countries to improve the guidelines to release the public platform. The fundamental purpose of the developing guidelines is to promote clinical practice, and to ensure that the guidelines' recommendations are applied, which is the key to achieve the goal. A number of studies ${ }^{[4,24]}$ in China and abroad find out that there is a large gap between the recommended guidelines and clinical practice, for the process of application of guidelines is affected by many factors, including the hospital environment, social environment, health care workers, patient compliance and many other aspects $^{[25-26]}$.

The results show that in the case of knowing of the recommendation, the main reasons for nurses not to use them include the recommendations being complex and difficult to implement, nurses' overload, clinical forming a fixed treatment and care programs, lacking of support and lack of related equipment resources. On the one hand, despite the rapid development of Chinese ostomy and evidence-based nursing, and clinical nurses improving their educational level, due to the busy clinical work, nurses have little time to learn the scientific knowledge and improve their ability. Most of the stoma nursing work is based on the initial diagnosis and treatment plan. These programs are depend on teaching materials, expert experience or clinical experience ${ }^{[27]}$. If the existing treatment and care programs can meet the needs of clinical ostomy care, nurses are less likely to try to apply new nursing measures. On the other hand, Yang ${ }^{[7]}$ and Rhodes et $a l^{[5]}$ pointed out that the organizational environment support directly affects the application of the guidelines. Most of the recommendations in this study were applied in hospitals. The enthusiasm of nurses in applying the guideline recommendations is related to whether the nurses can receive training and education on the guideline 
recommendations. In addition, some recommendations require special equipment resources, such as colon lavage and nutrition counseling. Therefore, clinical practice should be based on the selection of highly recommended recommendations, improving the department's attention and support, and optimizing equipment, and human resources, etc. to create a favorable environment for the application.

\section{Study limitations}

Limited by the conditions, this study used convenience sampling to investigate mainly the third-level (top-ranked) general hospitals in Beijing and Jiangsu Provinces, so the surveyed subjects in other areas were few, and sample representativeness had some limitations. Clinical stomatology nurses are mainly from those hospitals. Hence, this study only investigated those hospitals and did not include other levels of general hospitals and specialist hospitals, leading to limited results. Due to time constraints, this study only used a questionnaire survey of the status and influencing factors. Although some of the items were designed to be open, in-depth and specific. To a certain extent, the depth of this study was limited. The results of this study only show the knowledge and application of the recommendation, which cannot explain the clinical effect of applying specific recommendations. Therefore, this study only serves as a basis for the feasibility of the recommendations, but not evidence of opinion on the direct clinical application of a recommendation.

\section{Conclusion}

The overall knowledge and application is good, while the A-level recommendations were poorly understood and applied. Analysis of the reasons for the difference between the guideline recommendation and the application situation shows that advocacy is not enough and the lack of relevant education and training is unknown. However, even if they know the recommendation, the nurses do not always apply them because they are complex and difficult to implement, therefore, on the one hand, it is necessary to strengthen training and education and promote the knowledge of nurses. On the other hand, we should select feasible suggestions based on the clinical situation, and create a favorable application environment by improving the attention and support of departments.

\section{Declaration}

The authors declare that they have no competing interests.

\section{References}

1 Recalla S, English K, Nazarali R, et al. Ostomy care and management: a systematic review. J Wound Ostomy Continence Nurs, 2013, 40(5): 489-500.

2 Goldberg M, Aukett LK, Carmel J, et al. Management of the Patient With a Fecal Ostomy. J Wound Ostomy Continence Nurs, 2010, 37(6): 596-598.

3 Wound, Ostomy, and Continence Nurses Society. Pediatric Ostomy Care: Best Practice for Clinicians. [Online] Available from: http://www.wocn.org/ [Accessed on Dec. 22 2018].

4 Nothacker MJ. Guideline adherence - is more always better? Urologe A, 2016, 55(9): 1199-1205.

5 Rhodes L, Genders R, Owen R, et al. Investigating barriers to implementation of the NICE Guidelines for Depression: a staff survey with Community Mental Health Teams. J Psychiatr Ment Health Nurs, 2010, 17(2): 147-151.

6 Wu Mengjia, Zhang Jing, Zhou Zhichao, et al. Chinese clinical practice guide use and demand survey. Chin J Med Lib Info Sci, 2016, 25(1):37-42.

7 Yang J, Han C,Yoon HK, et al. Experiences and barriers to implementation of clinical practice guideline for depression in Korea[J]. BMC Psychiatry, 2013, 13: 150 .

8 Registered Nurses' Association of Ontario (RNAO). Ostomy Care, Management. 2009 [Online] Available from:https://rnao.ca/[Accessed on Dec. 23 2018].

9 Jayarajah U, Samarasekera DN. A cross-sectional study of quality of life in a cohort of enteral ostomy patients presenting to a tertiary care hospital in a developing country in South Asia. BMC Res Notes, 2017, 10(1): 75.

10 Reese JB, Finan PH, Haythornthwaite JA, et al. Gastrointestinal ostomies and sexual outcomes: a 
comparison of colorectal cancer patients by ostomy status. Support Care Cancer, 2014, 22(2): 461-468.

11 Mcnaughton V. Summary of best practice recommendations for management of enterocutaneous fistulae from the canadian association for enterostomal therapy ECF best practice recommendations panel. J Wound Ostomy Continence Nurs, 2010, 37(2): 173184.

12 Stenke E, Hussey S. Ulcerative colitis: management in adults, children and young people (NICE Clinical Guideline CG166). Arch Dis Child Educ Pract Ed, 2014, 99(5): 194-197.

13 World Council of Enterostomal Therapists(WCET). International Ostomy Guideline (2014). Available from: https://www.wcetn.org/ [Accessed on Dec. 25 2018].

14 Phatak UR, Li LT, Karanjawala B, et al. Systematic review of educational interventions for ostomates. Dis Colon Rectum, 2014, 57(4): 529-537.

15 Walker CA, Rau LA, Green MP. Welcoming home the patient with a new ostomy. Home Healthc Now, 2015, 33(7): 385-389.

16 Akmese ZB, Oran NT. Effects of progressive muscle relaxation exercises accompanied by music on low back pain and quality of life during pregnancy. $\mathrm{J}$ Midwifery Womens Health, 2014, 59(5): 503-509.

17 Demiralp M, Oflaz F, Komurcu S. Effects of relaxation training on sleep quality and fatigue in patients with breast cancer undergoing adjuvant chemotherapy. J Clin Nurs, 2010, 19(7/8): 1073-1083.

18 Hassanpour-Dehkordi A, Jalali A. Effect of progressive muscle relaxation on the fatigue and quality of life among iranian aging persons. Acta Med Iran, 2016, 54(7): 430-436.

19 Meyer B, Keller A, Wohlbier HG, et al. Progressive muscle relaxation reduces migraine frequency and normalizes amplitudes of contingent negative variation (CNV). J Headache Pain, 2016, 17: 37.

20 Sun J, Kang J,Wang P, et al. Self-relaxation training can improve sleep quality and cognitive functions in the older: a one-year randomised controlled trial. J Clin Nurs, 2013, 22(9-10): 1270-1280.

21 Moreno EM, Moriana JA. Clinical guideline implementation strategies for common mental health disorders. Rev Psiquiatr Salud Ment, 2016, 9(1): 5162.

22 Wang Dandan, Fu Xiaolin, Zheng Weifeng. Clinical nurses in China basic status of evidence-based practice and countermeasures. J Changchun Univ Trad Chin Med, 2015, 31(2): 396-398.

23 Liu Ai, Tang Chengxian, Chen Xingxing, et al. China's permanent colorectal cancer (artificial anus) patient care evidence. China Health Industry, 2014, 26(31): 85-86.

24 Fleuren MA, van Dommelen P, Dunnink T. A systematic approach to implementing and evaluating clinical guidelines: The results of fifteen years of Preventive Child Health Care guidelines in the Netherlands. Social Sci Med, 2015, 136-137: 35-43.

25 Arts DL, Voncken AG, Medlock S, et al. Reasons for intentional guideline non-adherence: A systematic review. Int J Med Inform, 2016, 89: 55-62.

26 Cahill NE, Heyland DK. Bridging the guidelinepractice gap in critical care nutrition: a review of guideline implementation studies. JPEN J Parenter Enteral Nutr, 2010, 34(6): 653-659.

27 Yang Ai-hua, YAN Mei, QIN Ya-hui. Current Status of Orthopedic Nursing in China and Abroad. Nurs Res, 2016, 30(1): 4-7. 


\section{Appendix}

1 Ostomy health education includes preoperative and postoperative parts, which are provided by specialist nurses such as wounds, stoma and incontinent nurses. Preoperative health education strategies include a brief discussion of gastrointestinal anatomy and physiology, the process of ostomy, demonstration of ostomy appliances, and a brief description of postoperative lifestyle adjustments.

2 Provide all available treatment plan information to patients and their families before surgery, including the benefits, risks and potential consequences of different treatment options. (no)

3 Preoperative education patients and their families (if possible) include stoma interpretation and stoma location, surgical procedures and postoperative stoma management methods. (IIB)

4 Postoperative health education should address key issues related to specific ostomy operations, such as physiological anatomy and function, basic skills in ostomy care, nutrition, clothing, drugs, body image, psychological problems, social entertainment, interpersonal relationships, sexual and Intimate relationships, common complications, available support resources, etc. (IA)

5 Health care providers can identify the potential impact of ostomy surgery on patient/companion intimate behavior and sexual function, and provide health guidance. (IIB)

6 Establish a therapeutic relationship with patients and their families. Nurses should pay close attention to the environment, condition, cause and type of surgery, nursing needs, and social support. (IIID)

7 Design a care plan that is accepted by both the patient/ family and the health care provider. This program optimizes patient health and self-efficacy in ostomy management. (IIID)

8 Guide the stoma patients for progressive muscle relaxation training as a daily health care. (IB)

9 The ostomy therapist or the clinician who had been ostomy educated the stoma in all patients who were undergoing ostomy. The position was the most prominent position of the umbilical lower rectus abdominis, away from abdominal scars, wrinkled skin folds or belts. (IIB)

10 Need to pay attention to the health-related quality of life (HRQOL) of patients after ostomy.(IV VC)

11 Ostomy nurses/doctors can recognize and identify the causes/risk factors of general stoma and surrounding skin complications. Such as: a stoma emergency surgery b stoma height c sex d age e newborn skin $\mathrm{f}$ fat $\mathrm{g}$ potential and current diseases, such as inflammatory bowel disease, diabetes h ostomy type. (II IIIB)

12 To monitor complications, use an effective tool to assess the stoma and surrounding skin immediately after surgery and to evaluate each time the pouch is replaced. (II $\sim$ IIIB)

13 Ensure patient comfort and activity by managing sputum effluent and protecting/curing skin/wound around the sputum

14 Patients, families, and ostomy nurses/doctors need to implement prevention and management programs to address potential or actual stoma and surrounding skin complications. (II IIIB)

15 Review the patient's medication records to ensure that patients with different stoma types can maximize drug absorption and ensure drug effectiveness; be aware of the role of adjuvant drug therapy and its impact and importance on ostomy function. (III-IVD)

16 Do not insert the glycerol plug into the colostomy for the discharge of feces. (IB)

17 Consult a registered dietitian to care for a stoma patient who is at risk or has had nutritional complications. (IIA)

18 Use one or more nutritional support strategies to prevent malnutrition or to treat existing undernutrition. (III-IVD)

19 Choose the appropriate ostomy skin care and ostomy bag according to the patient's condition, and have tools to help the nurse make choices to meet the needs of different patients and their families. (II $\sim$ IIIB)

20 Ostomy devices should provide predictable, reliable wear times. The ostomy pouch should be comfortable, deodorized and protected from the skin around the stoma. The wearing time should be at least three days, and it is recommended not to exceed seven days. 


\section{(IV $\sim \mathrm{VC})$}

21 After the patient has undergone ostomy, it is recommended that the ostomy teacher evaluate and follow up the patient and his family to reduce the psychological stress of the patient and family, improve their quality of life and prevent complications. (IIB)

22 Colonic lavage is a safe and effective method for managing adult patients with descending colon or sigmoid colostomy. (IIID)

23 Ostomy nurses need to pay attention to the impact of taking care of patients with stoma on the quality of life of their families. (II IIIB)

24 Conduct a comprehensive and comprehensive assessment of patients and their families and make appropriate care plans. The contents include: a history and physiological condition; b psychology (response and adaptation, body image, quality of life, sexual orientation and sexual concern); c culture, spiritual and religious forms; d economic factors. (IIB)

25 Establish a multidisciplinary team. All patients who need ostomy or existing stoma patients should consult with multidisciplinary teams according to their needs to jointly determine the nursing goals and ensure the quality of ostomy management. (III-IVD)

26 Conduct care programs to promote and support patients' return to the community, and provide home care support for discharged patients and their families. (IB)

27 Establish mechanisms for information transfer between health agencies to promote continuing education and clinical support for patients. Information about the patient's health status, postoperative progression, and ostomy education should be seamlessly communicated between the hospital and the community and between different medical institutions. (IVD)

28 In the academic environment and working environment, formulate policies, procedures and relevant staff training and education, and conduct ostomy education for all levels of health care providers to standardize the assessment and management methods. (IVD)

29 The ostomy therapist should be consulted during the ostomy education program to make the program suitable for health care providers, patients, families and carers. (IVD)

30 In the development of policy and project management, the organization should appoint qualified ostomy therapists. (IVD)

31 Organizations need to assess factors such as organization and personnel policies when making plans. (IVD) 